\title{
Influence of Exclusive Enteral Nutrition Therapy on Bone Density and Geometry in Newly Diagnosed Pediatric Crohn's Disease Patients
}

\author{
Katharina Julia Werkstetter Stephanie Barbara Schatz Martin Alberer \\ Birgit Filipiak-Pittroff Sibylle Koletzko \\ Division of Pediatric Gastroenterology and Hepatology, Dr. von Hauner Children's Hospital, University of Munich \\ Medical Center, Munich, Germany
}

\author{
Key Words \\ Children $\cdot$ Inflammatory bowel disease $\cdot$ Muscle . \\ Peripheral quantitative computed tomography
}

\begin{abstract}
Background and Aims: Exclusive enteral nutrition (EEN) induces remission in patients with Crohn's disease (CD). We investigated the short-term impact of EEN on bone quality and muscle mass in children with CD. Methods: Ten newly diagnosed CD patients (7 male, 10.6-17.7 years of age) were assessed by peripheral quantitative computed tomography (pQCT) at the forearm before starting an 8-weeks treatment with EEN, and after 12 and 52 weeks. No steroids or biologicals were applied. Trabecular and cortical bone mineral density, total bone, and muscle cross-sectional area (CSA) were measured by PQCT and expressed as age- and sex-specific z-scores; size-dependent CSAs were corrected for low height for age. Wilcoxon rank sum test was applied. Results: Remission at week 12 was achieved in 8 patients; 2 still had mild disease. Initially low trabecular density $z$-scores improved $(+0.3 ; p=0.006)$ at week 12 ; simultaneously, the increased cortical density $z$-scores normalized $(-0.4 ; p=0.027)$. The low $z$-score for muscle CSA corrected for height (median -2.5 , range -3.49 to -0.97$)$ increased within 12 weeks $(+1.0 ; p=$ 0.002) with no further improvement thereafter. Conclusions: The results indicate disturbed bone remodeling and
\end{abstract}

\section{KARGER}

E-Mail karger@karger.com

www.karger.com/anm severely impaired muscle mass in newly diagnosed CD children. Bone metabolism and muscle mass improved within 3 months after starting EEN with no further normalization thereafter.

Copyright $\odot 2013$ S. Karger AG, Basel

\section{Introduction}

In children with Crohn's disease (CD), exclusive enteral nutrition (EEN) therapy is as effective as systemic corticosteroids in inducing remission $[1,2]$ and even superior in terms of mucosal healing, side effects, correction of malnutrition, and patients' general well-being [3-6]. Furthermore, EEN may have additional benefits on bone health. Reduced bone density and increased fracture risk are well-known sequelae in CD patients [7]. Particularly, growing children and adolescents with $\mathrm{CD}$ are prone to disturbed bone metabolism. We and others have described low trabecular and high cortical density and alterations in bone geometry earlier in pediatric CD cohorts [8-10]. The combination of malnutrition, excessive inflammatory mediators, corticosteroid use, and reduced physical activity are the most important factors for impaired bone and muscle development during growth and may increase the risk for osteoporosis later in life $[7,10]$. EEN may help to reduce most of the detrimental effects

Sibylle Koletzko, MD, $\mathrm{PhD}$

Division of Pediatric Gastroenterology and Hepatology

Dr. von Hauner Children's Hospital, University of Munich Medical Center

Lindwurmstrasse 4, DE-80337 Munich (Germany)

E-Mail sibylle.koletzko@med.lmu.de 
of $\mathrm{CD}$ on bone health in pediatric patients. However, only few data are available, which are all of a retrospective nature or investigating bone markers only $[11,12]$.

The aim of this study was to investigate the short-term impact of nutritional therapy on bone mineral density, geometry, and muscle mass measured by peripheral quantitative computed tomography (pQCT) within 1 year after diagnosis and initial EEN treatment. Since bone strength depends not only on bone mineral content and bone density but also on bone geometry, pQCT is an excellent tool to locally assess true volumetric density, to distinguish between trabecular and cortical bone, and to assess total bone and muscle cross-sectional areas (CSAs) [13]. In addition, we monitored short-term effects of EEN on bone metabolism by several biomarkers.

\section{Materials and Methods}

Patients with newly diagnosed, active $\mathrm{CD}$ were recruited consecutively if they were between 6 and 18 years old. All patients were diagnosed according to ESPGHAN (European Society of Pediatric Gastroenterology, Hepatology and Nutrition) criteria [14] and started on EEN therapy after informed consent was signed. Exclusion criteria for recruitment were small bowel resection $(>100 \mathrm{~cm})$, ileostomy, other extra-intestinal organic or systemic diseases which may affect the nutritional status and/or bone metabolism, prior therapy with calcitonin, bisphosphonates, growth hormone or anabolic steroids, or current or recent participation in another clinical trial. If treatment with steroids or biologicals (e.g. infliximab) or surgery was indicated during the study, the patient was excluded from further analysis.

At diagnosis and at each follow-up visit at 4, 12, 24, and 52 weeks after the baseline visit, the recent medical history was recorded using a standardized questionnaire; physical examination, anthropometric measures, and grip strength were performed; pQCT was measured at diagnosis and at follow-up visits at week 12 and 52. To assess the disease activity, we calculated the Pediatric Crohn's Disease Activity Index (PCDAI) [15]. Scores $<10$ were considered as remission, between 10 and 27.5 as mild, between 30 and 37.5 as moderate, and $>37.5$ as severe disease activity.

For the EEN therapy, a liquid casein-based polymeric formula (Modulen ${ }^{\circledR}$; Nestlé, Frankfurt, Germany) was consumed orally or by nasogastric tube feeding for 8 weeks. During this period, only water and chewing gum was allowed. Formula volume was based on the estimated energy requirements for ideal weight for height. EEN was followed by a 2- to 4-week stepwise transition to normal diet, starting with low allergenic food, while formula volume was gradually decreased. Ongoing supplementation with enteral nutrition formula was not performed.

Anthropometry, Pubertal Stage, Bone Age, and Grip Force

Height was measured in a standing position to the nearest $1 \mathrm{~mm}$ with a digital telescopic wall-mounted stadiometer (Ulmer Stadiometer; Prof. E. Heinze, Ulm, Germany). Weight was determined to the nearest $0.1 \mathrm{~kg}$ using an electronic scale (Seca $753 \mathrm{E}$; Vogel and
Hanke, Hamburg, Germany), while the patients were undressed except for underwear. Body mass index (BMI) was calculated as weight $(\mathrm{kg}) /[\text { height }(\mathrm{m})]^{2}$. Height, weight, and BMI were compared with the longitudinal growth data of the German growth study [16].

The pubertal stage was assessed by the grading system of Tanner [17] (according to breast development in girls and testicular volume in boys) and grouped as follows: Tanner 1 (prepubertal), Tanner 2 and 3 (early pubertal), and Tanner 4 and 5 (adolescent).

Bone age was determined at diagnosis and week 52 by radiography of the left hand according to the method of Greulich and Pyle [18] to assess whether a comparison with the age-matched reference data was eligible. Patients were asked for previous bone fractures.

Maximal isometric grip force of the non-dominant hand was determined by an adjustable-handle Jamar Dynamometer (Preston, Jackson, Mich., USA). Reference data for forearm length and grip force were taken from the German DONALD (Dortmund Nutritional and Anthropometric Longitudinally Designed) study [19].

\section{Peripheral Quantitative Computed Tomography}

Bone and muscle parameters were measured by pQCT (XCT2000 scanner; Stratec, Pforzheim, Germany) as described previously [20]. In brief, at the nondominant forearm, the scanner was positioned corresponding to 4 and $65 \%$ of forearm length, and at both sites 2 -mm-thick single tomographic slices were measured with a voxel size of $0.4 \mathrm{~mm}$. Image processing and calculation of numerical values were performed by the manufacturer's software package (v.5.50; Stratec). At the $4 \%$ site (distal radius, metaphysis) trabecular bone mineral density and at the $65 \%$ site (proximal radius, diaphysis) cortical bone mineral density, total bone, and muscle CSA were determined.

The data were compared with reference data from 296 healthy German children and adolescents [21, 22]. As growth retardation is common in children and adolescents with inflammatory bowel disease, the bone size-dependent parameters (total and muscle CSA) were corrected for height (CSA $\left.{ }^{\text {height }}\right)$.

\section{Biomarkers of Inflammation and Bone Metabolism}

At baseline, week 12, 24, and 52, the following markers of inflammation were analyzed: erythrocyte sedimentation rate (ESR), $\mathrm{C}$-reactive protein (CRP), and fecal calprotectin. Bone parameters were analyzed as described previously [20] at baseline, week 4,12 , and 24 and included insulin-like growth factor 1 (IGF-1), insulinlike growth factor-binding protein 3 (IGF-BP), C-terminal propeptide of type I collagen (C1CP), bone-specific alkaline phosphatase (bsaP), intact parathyroid hormone (iPTH), desoxypyridinoline (DPD, urine), and $25-\mathrm{OH}$ vitamin $\mathrm{D}$. A $25-\mathrm{OH}$ vitamin D level $<10 \mathrm{ng} / \mathrm{ml}$ was considered as insufficient, between 10 and $20 \mathrm{ng} / \mathrm{ml}$ as deficient, and $>20 \mathrm{ng} / \mathrm{ml}$ as normal. In addition, vitamin K status was assessed by measuring plasma phylloquinone (vitamin K1) and PIVKA-II (prothrombin produced in vitamin $\mathrm{K}$ absence) [23]. Vitamin K1 was measured by high performance liquid chromatography; a suboptimal concentration was defined as $\leq 0.15 \mathrm{ng} / \mathrm{ml}$. PIVKA-II was analyzed by enzyme-linked immunosorbent assay. Values of $\geq 0.3 \mathrm{AU} / \mathrm{ml}$ were considered as abnormally increased.

\section{Statistics and Ethics}

Sex-, age-, and height-specific z-scores were calculated using the formula: $\mathrm{z}$-score $=[$ (test result for a patient $)-($ sex-, age-, or height-specific mean in reference population)]/(sex-, age-, or 
Table 1. Baseline characteristics of patients $(n=10)$

\begin{tabular}{ll}
\hline Variable & \\
\hline Male patients, $\mathrm{n}$ & 7 \\
Median age (range), years & $13.7(10.6 ; 17.7)$ \\
Median bone age (range), years & $13.5(8.5 ; 18.0)$ \\
Tanner staging, $\mathrm{n}$ & \\
$\quad$ Prepubertal/early pubertal/adolescent & $2 / 4 / 4$ \\
Disease localization, $\mathrm{n}$ & \\
$\quad$ Ileocolonic/colonic & $9 / 1$ \\
$\quad$ Upper gastrointestinal tract involved & 6 \\
$\quad$ Perianal fistula & 0 \\
\hline
\end{tabular}

height-specific standard deviation in reference population). To examine changes over time, individual differences in parameters between baseline and follow-up visits and differences between the follow-up visits were calculated. For all parameters and differences, median and range were given; Wilcoxon rank sum test was applied to test the differences and z-scores. Spearman correlation was applied to examine associations between changes in bone biomarkers and changes in pQCT parameters. For all tests, a p value $<0.05$ was regarded as significant.

The study protocol was approved by the Federal Office for Radiation Protection (Salzgitter, Germany; approval Z5-22462/22004-051) and the Ethical Committee of the Medical Faculty of the University of Munich (project 202/04). Written informed consent was obtained from all parents and patients.

\section{Results}

Fifteen patients with newly diagnosed CD had been identified as eligible to participate. Two patients refused to participate in the study. Of the 13 included patients, 1 patient had to be excluded from the study at 4 weeks and 2 patients at 12 weeks because they required treatment with biologicals due to worsening of perianal fistulizing disease.

The basic characteristics of the 10 patients with complete follow-up are summarized in table 1 . Two patients showed mild (1 year) and 1 patient severe ( 2 years) retardation in bone age at diagnosis. The median difference between bone age and chronological age was -0.3 years (range -2.2 to 0.6 ). None of the patients reported previous bone fractures.

All 10 patients completed 8 weeks of EEN. In parallel, all patients started azathioprine therapy with a median time gap of 8 days (range 0 to 29 days) after induction of EEN; 9 patients started 5-aminosalicyl-acid (5-ASA) therapy with a median time gap of 5 days (range 0 to 14 days) after EEN. During follow-up, all patients continued azathioprine and 5-ASA therapy. None of them re- ceived steroids or biologicals between baseline and week 52 . Five patients received proton-pump inhibitors, and 1 patient was treated with antibiotics at week 24 .

According to the PCDAI, most of the patients had mild to moderate disease activity at diagnosis (table 2). Twelve weeks after initiation of therapy, 8 patients were in remission and 2 had mild disease (PCDAI 10 and 25). Between week 12 and 52, 7 of 10 patients relapsed; 4 of them repeated EEN between week 24 and 52 .

Bone biomarkers at diagnosis and differences between follow-ups are summarized in table 3. Significant increases from baseline to week 4 or 12 were detected for $\mathrm{iPTH}$, bsaP, C1CP, IGF-1, IGF-BP, and DPD (the latter only for baseline to week 4). No significant changes were seen between week 12 and 24. PIVKA-II was normal or below detection level for all patients at diagnosis and during follow-up (data not shown).

Z-scores for height and BMI were impaired at baseline but increased significantly for BMI within the 12 weeks after initiation of EEN (table 4). Height $\mathrm{z}$-scores did not improve. Trabecular density z-scores seemed to be low, while cortical density $z$-scores tended to be increased at baseline, both without reaching statistical significance; total CSA ${ }^{\text {height }} \mathrm{z}$-scores were on a normal level. Between baseline and week 12, trabecular density (table 4, fig. 1, and online suppl. fig., www.karger.com/doi/10.1159/ 000350369) and total CSA height $\mathrm{z}$-scores significantly increased, while initially high cortical-density $\mathrm{z}$-scores decreased towards normal (table 4, fig. 1, and online suppl. fig.). Both muscle CSA height and grip strength $\mathrm{z}$-scores were markedly reduced at diagnosis and clearly improved after EEN had been completed (table 4, fig. 1).

For all anthropometric and pQCT parameters, significant changes in $\mathrm{z}$-scores were only detected in the first 12 weeks after initiation of EEN but not between later follow-up visits (table 4); a similar observation was made regarding the changes in bone biomarkers (table 3 ). When we correlated the changes of bone biomarkers (baseline to week 4 ) with changes in bone density z-scores (baseline to week 12), a trend towards a positive association between $\mathrm{C} 1 \mathrm{CP}$ and trabecular density $(\mathrm{r}=0.65 ; \mathrm{p}=$ 0.057 ) or a trend towards a negative correlation between $\mathrm{C} 1 \mathrm{CP}$ and cortical density $(\mathrm{r}=-0.61 ; \mathrm{p}=0.081)$ was seen.

\section{Discussion}

To our knowledge, this is the first study to assess shortterm effects of EEN not only on bone biomarkers but also on bone density and geometry in newly diagnosed pedi-
Werkstetter/Schatz/Alberer/ Filipiak-Pittroff/Koletzko 
Table 2. PCDAI, CRP, ESR, and calprotectin as parameters of disease activity at baseline and follow-up visits

\begin{tabular}{lllll}
\hline & Baseline & 12 weeks & 24 weeks & 52 weeks \\
\hline $\begin{array}{l}\text { PCDAI } \\
\quad \text { Remission/mild/moderate/severe activity, n }\end{array}$ & $0 / 3 / 5 / 2$ & $8 / 1 / 1 / 0$ & $5 / 4 / 0 / 1$ & $7 / 2 / 0 / 1$ \\
\hline $\begin{array}{l}\text { Median CRP (range), mg/dl } \\
\quad>0.5 \mathrm{mg} / \mathrm{dl}, \mathrm{n} / \text { total }\end{array}$ & $2.3(0.3 ; 5.0)$ & $0.3(0.1 ; 3.1)$ & $0.1(0.6 ; 7.0)$ & $0.2(0.1 ; 3.7)$ \\
\hline $\begin{array}{l}\text { Median ESR (range), mm/h } \\
>15 \mathrm{~mm} / \mathrm{h}, \mathrm{n} / \text { total }\end{array}$ & $4 / 10$ & $7 / 10$ & $5 / 10$ & $24(10 ; 53)$ \\
\hline $\begin{array}{l}\text { Median calprotectin (range), mg/g } \\
>50 \mathrm{mg} / \mathrm{g} \text { feces, n/total }\end{array}$ & $8 / 10$ & $28(6 ; 51)$ & $7 / 10$ & $7 / 10$ \\
\hline
\end{tabular}

Values are number of patients for PCDAI, and median (range) and proportion of patients above the normal limit for CRP, ESR, and calprotectin.

Table 3. Bone biomarkers at baseline

\begin{tabular}{|c|c|c|c|c|}
\hline & Baseline & $\begin{array}{l}\text { Differences } \\
\text { baseline to week } 4\end{array}$ & $\begin{array}{l}\text { Differences } \\
\text { baseline to week } 12\end{array}$ & $\begin{array}{l}\text { Differences } \\
\text { week 12-24 }\end{array}$ \\
\hline $\begin{array}{l}\text { Vitamin } \mathrm{K} 1, \mathrm{ng} / \mathrm{ml} \\
\leq 0.15 \mathrm{ng} / \mathrm{ml}\end{array}$ & $\begin{array}{l}0.17(0.05 ; 2.68) \\
5 / 10\end{array}$ & $\begin{array}{l}0.41(-2.32 ; 0.73) \\
\mathrm{p}=0.250\end{array}$ & $\begin{array}{l}0.0(-2.59 ; 0.56) \\
\mathrm{p}=0.461\end{array}$ & Not done \\
\hline $\begin{array}{l}25-\mathrm{OH} \text { vitamin } \mathrm{D}, \mathrm{ng} / \mathrm{ml} \\
\quad<20 \mathrm{ng} / \mathrm{ml}\end{array}$ & $\begin{array}{l}24.8(10.6 ; 32.0) \\
3 / 10\end{array}$ & $\begin{array}{l}2.5(-7.9 ; 13.8)^{b} \\
p=0.426\end{array}$ & $\begin{array}{l}3.1(-12.0 ; 19.2) \\
p=0.061\end{array}$ & $\begin{array}{l}0.65(-25.5 ; 15.5)^{\mathrm{c}} \\
\mathrm{p}=0.945\end{array}$ \\
\hline $\begin{array}{l}\mathrm{iPTH}, \mathrm{pg} / \mathrm{ml} \\
>\text { normal limit }^{\mathrm{a}}\end{array}$ & $\begin{array}{l}23.0(17.1 ; 45.4) \\
1 / 10\end{array}$ & $\begin{array}{l}7.4(1.5 ; 15.6) \\
p=0.002\end{array}$ & $\begin{array}{l}15.0(-8.7 ; 34.9)^{b} \\
p=0.016\end{array}$ & $\begin{array}{l}4.8(-8.7 ; 26.9)^{b} \\
p=0.250\end{array}$ \\
\hline $\begin{array}{l}\text { bsaP, U/l } \\
\quad<\text { normal limit }^{\text {a }}\end{array}$ & $\begin{array}{l}47(31 ; 74) \\
0 / 10\end{array}$ & $\begin{array}{l}24(-5 ; 123)^{b} \\
p=0.012\end{array}$ & $\begin{array}{l}34(12 ; 113)^{b} \\
p=0.004\end{array}$ & $\begin{array}{l}-20(-85 ; 39)^{b} \\
p=0.193\end{array}$ \\
\hline $\begin{array}{l}\mathrm{C} 1 \mathrm{CP}, \mathrm{ng} / \mathrm{ml} \\
<\text { normal limit }^{\mathrm{a}}\end{array}$ & $\begin{array}{l}83.5(48 ; 236) \\
6 / 10\end{array}$ & $\begin{array}{l}156(56 ; 362)^{b} \\
p=0.004\end{array}$ & $\begin{array}{l}113(31 ; 530)^{b} \\
p=0.004\end{array}$ & $\begin{array}{l}-53(-114 ; 166)^{b} \\
p=0.641\end{array}$ \\
\hline $\begin{array}{l}\text { IGF-1, ng/ml } \\
\quad<\text { normal limit }^{\text {a }}\end{array}$ & $\begin{array}{l}112(41 ; 283) \\
7 / 10\end{array}$ & $\begin{array}{l}158(-39 ; 272)^{b} \\
p=0.008\end{array}$ & $\begin{array}{l}161(13 ; 255)^{b} \\
p=0.004\end{array}$ & $\begin{array}{l}-2(-76 ; 99)^{b} \\
p=0.910\end{array}$ \\
\hline $\begin{array}{l}\text { IGF-BP, } \mu \mathrm{g} / \mathrm{ml} \\
\quad<\text { normal limit }^{\mathrm{a}}\end{array}$ & $\begin{array}{l}3.3(0.8 ; 4.3) \\
1 / 10\end{array}$ & $\begin{array}{l}1.7(-0.1 ; 3.0)^{b} \\
p=0.008\end{array}$ & $\begin{array}{l}0.9(-0.3 ; 2.1)^{b} \\
p=0.012\end{array}$ & $\begin{array}{l}0.0(-0.7 ; 1.4)^{b} \\
p=0.867\end{array}$ \\
\hline $\begin{array}{c}\mathrm{DPD}, \mu \mathrm{g} / \mathrm{g} \text { Creatinin } \\
>\text { normal limit }^{\mathrm{a}}\end{array}$ & $\begin{array}{l}202(115 ; 467)^{b} \\
0 / 10\end{array}$ & $\begin{array}{l}64.5(-28 ; 637)^{c} \\
p=0.039\end{array}$ & $\begin{array}{l}36(-75 ; 165)^{\mathrm{c}} \\
\mathrm{p}=0.219\end{array}$ & $\begin{array}{l}-30.5(-146 ; 46)^{c} \\
p=0.078\end{array}$ \\
\hline
\end{tabular}

Values are median (range) and proportion of patients with abnormal values compared to age- and sex-specific normal values; differences between follow-up analysis: median (range) and p value. ${ }^{\text {a }}$ Related to age- and sex-specific normal values. ${ }^{b}$ Number of patients: 9. ${ }^{\mathrm{c}}$ Number of patients: 8 .

atric CD patients. Unexpectedly, we observed significant changes towards normalization only within 3 months after initial diagnosis and treatment with EEN. Our data support the hypothesis that EEN positively affects bone and muscle parameters in newly diagnosed pediatric $C D$ patients.

Nutrition Therapy and Bone in Pediatric Crohn's Disease
As previously described, low trabecular plus high cortical density indicate disturbed bone turnover, which is frequent in children and adolescents with $\mathrm{CD}[8,9]$. In the present cohort, trabecular bone mineral density increased, while high cortical density normalized, most likely due to enhanced remodeling in the cortical bone and formation 
Table 4. Z-scores for height, BMI, trabecular and cortical density, total and muscle CSA ${ }^{\text {height }}$, and grip strength at baseline compared to reference population and differences between measurements

\begin{tabular}{|c|c|c|c|c|c|c|}
\hline & \multicolumn{2}{|c|}{ Baseline z-scores compared to reference } & \multicolumn{2}{|c|}{$\mathrm{z}$-score differences baseline to week 12} & \multicolumn{2}{|c|}{$\mathrm{z}$-score differences week $12-52$} \\
\hline BMI & $-1.25(-2.02 ; 0.18)$ & 0.004 & $0.53(-0.29 ; 0.92)$ & 0.006 & $0.05(-1.56 ; 1.35)$ & 0.625 \\
\hline Trabecular density & $-0.78(-1.96 ; 1.37)$ & 0.193 & $0.30(-0.03 ; 0.99)$ & 0.006 & $0.35(-1.81 ; 1.19)$ & 0.432 \\
\hline Cortical density & $0.91(-0.42 ; 2.24)$ & 0.065 & $-0.40(-1.07 ; 0.49)$ & 0.027 & $-0.08(-0.92 ; 1.27)$ & 0.625 \\
\hline Grip strength & $-1.73(-2.84 ; 0.82)$ & 0.020 & $0.74(-0.99 ; 2.80)$ & 0.065 & $0.36(-1.55 ; 2.71)$ & 0.492 \\
\hline
\end{tabular}

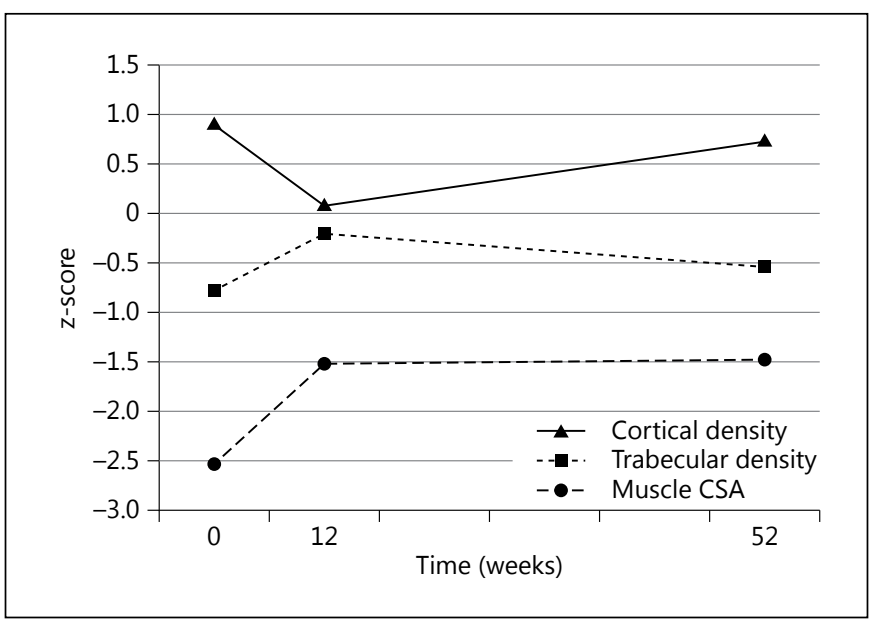

Fig. 1. Development of $\mathrm{z}$-score medians for trabecular and cortical density, and muscle CSA height.

of new Haversian canals. Reduced muscle CSA and grip strength clearly improved during initial nutritional therapy but not afterwards. In parallel, $\mathrm{C} 1 \mathrm{CP}$ and bsaP as biomarkers of bone formation increased significantly; DPD as a parameter of bone resorption also increased, probably due to overall improved bone remodeling, which requires not only bone formation, but also resorption during growth and skeletal development [24]. Similar effects of EEN on normalization of bone biomarkers had already been reported in Australian pediatric CD patients [11].

Several potential mechanisms of EEN on bone metabolism had been postulated. A rapid decrease of proinflammatory markers and cytokines, such as CRP, ESR, and IL-6, within the first week of EEN had been shown earlier in pediatric CD patients [25]. Decrease of inflammation most likely led to normalization of bone modeling in our patients, resulting in increased bone formation in the trabecular bone and normalization of low level of bone remodeling in the cortical bone. Two studies in adult and pediatric CD patients had shown similar shortterm effects on bone biomarkers after induction of remission with infliximab $[24,26]$. However, both studies did not apply pQCT to investigate the changes in the different bone compartments and the muscle mass.

Correction of malnutrition is another potential factor for improving bone health by EEN. CD patients frequently present with protein-energy malnutrition at diagnosis and deficiency of micronutrients [27]. EEN may have direct effects on bone metabolism by providing important micronutrients such as calcium, which is the main bone mineral, and vitamin $\mathrm{D}$, which regulates serum calcium levels; vitamin $\mathrm{K}$ is important for carboxylation of osteocalcin, the major noncollagenous protein in bones [28]. However, in our cohort, no association between changes in vitamin $\mathrm{D}$ and $\mathrm{K}$ levels and bone parameters were observed. More likely, EEN influences bone accrual indirectly by correction of protein-energy malnutrition. We consider that the high increase in IGF-1 and C1CP during EEN reflects improved nutritional status, and both parameters are positively associated with bone modeling. Secondly, the gain in muscle mass is at least in part a consequence of improved protein-energy supply. The concept of a muscle-bone unit suggests that muscle strength strongly modulates bone strength [29]. This strong association was confirmed in our prospective long-term study and applies to pediatric inflammatory bowel disease patients both with $\mathrm{CD}$ and ulcerative colitis [9]. In addition, improvements in muscle mass and increased general well-being may have increased the physical activity of our patients after starting on EEN and this may also have contributed to the changes in bone density and structure. 
The impact of corticosteroid therapy on bone health in CD patients is still controversially discussed [7]. Shortterm therapy with corticosteroids does not appear to negatively affect bone mineral density [9]. A British study in 95 adult women with CD showed that patients who were treated predominantly with nutritional therapy or only small lifetime doses of steroids $(<5 \mathrm{~g})$ or no steroids at all did not differ from controls in their bone density. In contrast, patients with a lifetime dose of $>5$ g prednisolone had a significantly lower bone mineral density than ageand gender-matched controls [12].

Our study has several strengths and limitations. An advantage is that the study group was relatively homogenous, including only newly diagnosed patients without fistulizing disease. The major advantage was the use of pQCT instead of commonly applied dual energy X-ray absorptiometry, which has the drawbacks that it measures bone mass $\left(\mathrm{g} / \mathrm{cm}^{2}\right)$ only, is subject to growth-related artifacts, and systemically underestimates the bone density of stunted individuals [13]. As the radiation dose is extremely low with $0.6 \mu \mathrm{Sv}$, pQCT is highly suitable for a longitudinal investigation in children and adolescents. The close follow-up of our patients already 12 weeks after initiation of EEN is another important strength of our study which enabled us to detect the positive short-term effects of EEN on bone structure. In addition, pQCT measurements were supported by the changes in bone biomarkers.

The major limitations are the small sample size and the lack of a control group of CD patients treated with corticosteroids or infliximab for induction of remission. Therefore, it remains unclear whether EEN is superior, for example, compared to infliximab in terms of better improvement of bone parameters due to potential nutritional effects. However, due to ethical considerations it was not possible to have such a control group since EEN is already well established as a first-line therapy in Europe [14]. Therefore, the strength of our results is limited and we can only speculate on the mechanisms responsible for the positive effect of EEN on bone health. All patients started on azathioprine during EEN. However, this drug develops its main efficacy only after 2-4 months. The follow-up at 3 months showed the greatest improvement in bone modeling and biomarkers, while there was no further improvement thereafter in spite of continued azathioprine therapy.

In conclusion, low trabecular and high cortical bone density at diagnosis indicate disturbed bone remodeling. Muscle CSA, corrected for low height for age, as well as grip strength were significantly impaired. Within only 3 months after initiation of EEN therapy, bone metabolism and muscle mass significantly improved towards normalization, most likely due to reduced inflammation in combination with nutritional support. Further investigations are needed to evaluate the impact and mechanisms of EEN on bone and muscle development in newly diagnosed pediatric CD patients, preferably in comparison to a control group treated with steroids or biologicals. In addition, the effect of partial enteral nutrition (for example, nighttime feeding, with a normal diet during the day) to further improve bone health and muscle mass in pediatric CD patients should be evaluated.

\section{Acknowledgement}

We thank our colleague Susanne Bechtold-Dalla Pozza for reviewing the manuscript and Prof. Berthold Koletzko for providing the PQCT machine. Vitamin K1 and PIVKA-II had been measured in cooperation with Martin Shearer's Lab, St. Thomas' Hospital, London, UK. The study was financially supported by Nestec Ltd., Vevey, Switzerland.

\section{Disclosure Statement}

K.J.W., S.B.S., M.A., and B.F.-P. have no conflicts of interest. S.K. was financially supported by Nestec Ltd., Vevey, Switzerland.

\section{References}

1 Dziechciarz P, Horvath A, Shamir R, Szajewska $\mathrm{H}$ : Meta-analysis: enteral nutrition in active Crohn's disease in children. Aliment Pharmacol Ther 2007;26:795-806.

- 2 Heuschkel RB, Menache CC, Megerian JT, Baird AE: Enteral nutrition and corticosteroids in the treatment of acute Crohn's disease in children. J Pediatr Gastroenterol Nutr 2000;31:8-15.

$\checkmark 3$ Afzal NA, Van Der Zaag-Loonen HJ, ArnaudBattandier F, Davies S, Murch S, Derkx B, Heuschkel R, Fell JM: Improvement in qual- ity of life of children with acute Crohn's disease does not parallel mucosal healing after treatment with exclusive enteral nutrition. Aliment Pharmacol Ther 2004;20:167-172.

$\checkmark 4$ Cucchiara S, Escher JC, Hildebrand H, AmilDias J, Stronati L, Ruemmele FM: Pediatric inflammatory bowel diseases and the risk of lymphoma: should we revise our treatment strategies? J Pediatr Gastroenterol Nutr 2009; 48:257-267.

5 Fell JM, Paintin M, Arnaud-Battandier F, Beattie RM, Hollis A, Kitching P, Donnet-Hughes
A, MacDonald TT, Walker-Smith JA: Mucosal healing and a fall in mucosal pro-inflammatory cytokine mRNA induced by a specific oral polymeric diet in paediatric Crohn's disease. Aliment Pharmacol Ther 2000;14:281-289.

6 Heuschkel R: Enteral nutrition should be used to induce remission in childhood Crohn's disease. Dig Dis 2009;27:297-305.

7 Hill RJ, Brookes DSK, Davies PSW: Bones in pediatric Crohn's disease: a review of fracture risk in children and adults. Inflamm Bowel Dis 2011;17:1223-1228. 
8 Dubner SE, Shults J, Baldassano RN, Zemel BS, Thayu M, Burnham JM, Herskovitz RM, Howard KM, Leonard MB: Longitudinal assessment of bone density and structure in an incident cohort of children with Crohn's disease. Gastroenterology 2009;136:123-130.

-9 Werkstetter KJ, Pozza SBD, Filipiak-Pittroff B, Schatz SB, Prell C, Bufler P, Koletzko B, Koletzko S: Long-term development of bone geometry and muscle in pediatric inflammatory bowel disease. Am J Gastroenterol 2011;106:988-998.

10 Werkstetter KJ, Ullrich J, Schatz SB, Prell C, Koletzko B, Koletzko S: Lean body mass, physical activity and quality of life in paediatric patients with inflammatory bowel disease and in healthy controls. J Crohns Colitis 2012; 6:665-673.

11 Whitten K, Leach S, Bohane T, Woodhead H, Day A: Effect of exclusive enteral nutrition on bone turnover in children with Crohn's disease. J Gastroenterol 2010;45:399-405.

$\checkmark 12$ Dear KL, Compston JE, Hunter JO: Treatments for Crohn's disease that minimise steroid doses are associated with a reduced risk of osteoporosis. Clin Nutr 2001;20:541-546.

$\checkmark 13$ Binkley TL, Berry R, Specker BL: Methods for measurement of pediatric bone. Rev Endocr Metab Disord 2008;9:95-106.

$\checkmark 14$ Van Assche G, Dignass A, Reinisch W, van der Woude CJ, Sturm A, De Vos M, Guslandi M, Oldenburg B, Dotan I, Marteau P, Ardizzone A, Baumgart DC, D’Haens G, Gionchetti P, Portela F, Vucelic B, Söderholm J, Escher J, Koletzko S, Kolho KL, Lukas M, Mottet C, Tilg H, Vermeire S, Carbonnel F, Cole A, Novacek $G$, Reinshagen $M$, Tsianos E, Herrlinger K, Bouhnik Y, Kiesslich R, Stange E, Travis S, Lindsay J: The second European evidencebased consensus on the diagnosis and management of Crohn's disease: special situations. J Crohns Colitis 2010;4:63-101.
15 Hyams JS, Ferry GD, Mandel FS, Gryboski JD, Kibort PM, Kirschner BS, Griffiths AM, Katz AJ, Grand RJ, Boyle JT, et al: Development and validation of a pediatric Crohn's disease activity index. J Pediatr Gastroenterol Nutr 1991;12:439-447.

16 Brandt I, Reinken L: Die Wachstumsgeschwindigkeit gesunder Kinder in den ersten 16 Lebensjahren: Longitudinale Entwicklungsstudie Bonn-Dortmund. Klin Padiatr 1988;200:451-456.

17 Tanner JM: Growth at Adolescence, ed 2. Oxford, Blackwell Scientific, 1962.

18 Greulich WW, Pyle SI: Radiographic Atlas of Skeletal Development of the Hand and Wrist, ed 2. Palo Alto, CA, Standford University Press, 1971.

19 Rauch F, Neu CM, Wassmer G, Beck B, Rieger-Wettengl G, Rietschel E, Manz F, Schoenau E: Muscle analysis by measurement of maximal isometric grip force: new reference data and clinical applications in pediatrics. Pediatr Res 2002;51:505-510.

20 Bechtold S, Alberer M, Arenz T, Putzker S, Filipiak-Pittroff B, Schwarz HP, Koletzko S: Reduced muscle mass and bone size in pediatric patients with inflammatory bowel disease. Inflamm Bowel Dis 2010;16:216-225.

21 Neu CM, Manz F, Rauch F, Merkel A, Schoenau E: Bone densities and bone size at the distal radius in healthy children and adolescents: a study using peripheral quantitative computed tomography. Bone 2001;28:227-232.

22 Neu CM, Rauch F, Manz F, Schœnau E: Modeling of cross-sectional bone size, mass and geometry at the proximal radius: a study of normal bone development using peripheral quantitative computed tomography. Osteoporos Int 2001;12:538-547.
23 Conway SP, Wolfe SP, Brownlee KG, White H, Oldroyd B, Truscott JG, Harvey JM, Shearer MJ: Vitamin K status among children with cystic fibrosis and its relationship to bone mineral density and bone turnover. Pediatrics 2005;115:1325-1331.

24 Thayu M, Leonard MB, Hyams JS, Crandall WV, Kugathasan S, Otley AR, Olson A, Johanns J, Marano CW, Heuschkel RB, Veereman-Wauters G, Griffiths AM, Baldassano $\mathrm{RN}$ : Improvement in biomarkers of bone formation during infliximab therapy in pediatric Crohn's disease: results of the REACH study. Clin Gastroenterol Hepatol 2008;6:13781384.

25 Bannerjee K, Camacho-Hübner C, Babinska K, Dryhurst KM, Edwards R, Savage MO, Sanderson IR, Croft NM: Anti-inflammatory and growth-stimulating effects precede nutritional restitution during enteral feeding in Crohn disease. J Pediatr Gastroenterol Nutr 2004;38:270-275.

26 Franchimont N, Putzeys V, Collette J, Vermeire S, Rutgeerts P, De Vos M, Van Gossum A, Franchimont D, Fiasse R, Pelckmans P, Malaise M, Belaiche J, Louis E: Rapid improvement of bone metabolism after infliximab treatment in Crohn's disease. Aliment Pharmacol Ther 2004;20: 607-614.

27 Gerasimidis K, McGrogan P, Edwards CA: The aetiology and impact of malnutrition in paediatric inflammatory bowel disease. J Hum Nutr Diet 2011;24:313-326.

28 Palacios C: The role of nutrients in bone health, from A to Z. Crit Rev Food Sci Nutr 2006;46:621-628.

29 Frost HM, Schönau E: The 'muscle-bone unit' in children and adolescents: a 2000 overview. J Pediatr Endocrinol Metab 2000; 13:571-590. 